\title{
Experimental Evaluation of SI Engine Operation Supplemented by Hydrogen Rich Gas from a Compact Plasma Boosted Reformer
}

J. B. Green, Jr., N. Domingo, J. M. E. Storey, R. M. Wagner and J. S. Armfield Oak Ridge National Lab.

L. Bromberg, D. R. Cohn, A. Rabinovich and N. Alexeev MIT Plasma Science and Fusion Center 
SAE routinely stocks printed papers for a period of three years following date of publication. Direct your orders to SAE Customer Sales and Satisfaction Department.

Quantity reprint rates can be obtained from the Customer Sales and Satisfaction Department.

To request permission to reprint a technical paper or permission to use copyrighted SAE publications in other works, contact the SAE Publications Group.

This article was prepared as an account of work sponsored by an agency of the United States

Government. Neither the United States Government nor any agency thereof, nor any of their employees, makes any warranty, express or implied, or assumes any legal liability or responsibility for the accuracy, completeness, or usefulness of any information, apparatus, product, or process disclosed, or represents that its use would not infringe privately owned rights. Reference herein to any specific commercial product, process, or service by trade name, trademark, manufacturer, or otherwise does not necessarily constitute or imply its endorsement, recommendation, or favoring by the United States Government or any agency thereof. The views and opinions of authors expressed herein do not necessarily state or reflect those of the United States Government or any agency thereof.

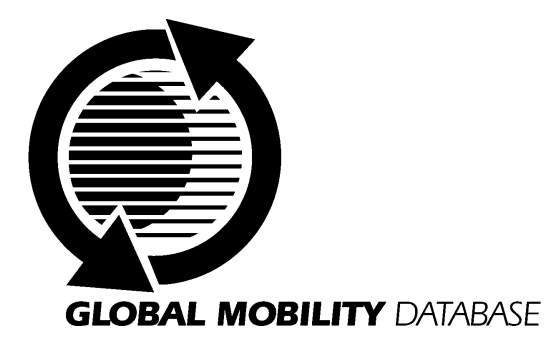

All SAE papers, standards, and selected books are abstracted and indexed in the Global Mobility Database

ISSN 0148-7191

No copyright is asserted in the works of U.S. Government employees.

Positions and opinions advanced in this paper are those of the author(s) and not necessarily those of SAE. The author is solely responsible for the content of the paper. A process is available by which discussions will be printed with the paper if it is published in SAE Transactions. For permission to publish this paper in full or in part, contact the SAE Publications Group.

Persons wishing to submit papers to be considered for presentation or publication through SAE should send the manuscript or a 300 word abstract of a proposed manuscript to: Secretary, Engineering Meetings Board, SAE.

\section{Printed in USA}




\title{
Experimental Evaluation of SI Engine Operation Supplemented by Hydrogen Rich Gas from a Compact Plasma Boosted Reformer
}

\author{
J. B. Green, Jr., N. Domingo, J. M. E. Storey, \\ R. M. Wagner and J. S. Armfield \\ Oak Ridge National Lab. \\ L. Bromberg, D. R. Cohn, A. Rabinovich and N. Alexeev \\ MIT Plasma Science and Fusion Center
}

No copyright is asserted in the works of U.S. Government employees

\begin{abstract}
It is well known that hydrogen addition to spark-ignited (SI) engines can reduce exhaust emissions and increase efficiency. Micro plasmatron fuel converters can be used for onboard generation of hydrogen-rich gas by partial oxidation of a wide range of fuels. These plasmaboosted microreformers are compact, rugged, and provide rapid response. With hydrogen supplement to the main fuel, $\mathrm{SI}$ engines can run very lean resulting in a large reduction in nitrogen oxides $\left(\mathrm{NO}_{\mathrm{x}}\right)$ emissions relative to stoichiometric combustion without a catalytic converter. This paper presents experimental results from a microplasmatron fuel converter operating under variable oxygen to carbon ratios. Tests have also been carried out to evaluate the effect of the addition of a microplasmatron fuel converter generated gas in a 1995 2.3-L fourcylinder SI production engine. The tests were performed with and without hydrogen-rich gas produced by the plasma boosted fuel converter with gasoline. A one hundred fold reduction in $\mathrm{NO}_{\mathrm{x}}$ due to very lean operation was obtained under certain conditions. An advantage of onboard plasma- boosted generation of hydrogen-rich gas is that it is used only when required and can be readily turned on and off. Substantial $\mathrm{NO}_{\mathrm{x}}$ reduction should also be obtainable by heavy exhaust gas recirculation (EGR) facilitated by use of hydrogen-rich gas with stoichiometric operation.
\end{abstract}

\section{INTRODUCTION}

Decreasing emissions from automobiles and increasing engine efficiency are necessary steps toward improving air quality and decreasing greenhouse gases. Transportation vehicles are the largest consumer of imported oil and a major source of pollutants that affect urban areas. A variety of potential improvements are currently being investigated: spark-ignited direct-injection engines, new catalyst formulations, close coupled catalysts, new types of exhaust aftertreatment, electric and fuel-cell powered vehicles, and alternative fuels.

Large reductions in emissions from SI engines are possible by operation under lean conditions with the addition of hydrogen. Hydrogen increases flame speed and extends the lean limit of SI engine operation [1]. The combination of enhanced flame speed and wider flammability limits of hydrogen can thus stabilize combustion during lean operation. Thus, a concept that could substantially reduce emissions is onboard hydrogen generation using microplasmatron fuel converters. Plasmatrons are electrical gas heaters that make use of the conductivity of gases at high temperature. Microplasmatron fuel converters are compact, rugged, compatible with several fuels, and able to respond rapidly.

Very lean fueling of SI engines could reduce $\mathrm{NO}_{x}$ emissions by a factor of one hundred relative to $\mathrm{NO}_{\mathrm{x}}$ emissions at stoichiometric fueling $[2,3,4]$. Hydrogen addition could also be used to reduce $\mathrm{NO}_{\mathrm{x}}$ emissions by facilitating the use of increased exhaust gas recirculation (EGR) [5]. Onboard production of hydrogen is also attractive for reduction of cold start emissions, as well as for lean NOx catalyst regeneration and post treatment.

Concepts for utilizing plasmatron generated hydrogenrich gasoline in SI engines have been discussed in previous papers [6-9]. Engine experiments have also been performed using bottled synthesis gas $[2,3,4,10]$ and conventional reformers operating on methane [11] or ethanol $[12,13]$. To the knowledge of the authors, this paper reports the first use of a compact plasma boosted reformer to convert gasoline into hydrogen-rich gas for the purpose of stabilizing lean combustion in a SI engine. 


\section{COMPACT PLASMA BOOSTED REFORMERS}

Plasmatrons provide highly controllable, ohmic heating of gases to elevated temperatures. At these temperatures, the gas is partially ionized. The increased temperatures, ionization levels, and mixing provided by plasmatron heating accelerate reformation of hydrocarbon fuels into hydrogen rich gas. The high temperatures can be used for reforming a wide range of hydrocarbon fuels into hydrogen-rich gas without using a catalyst. Thus, it is possible to eliminate problems associated with catalyst use, such as narrow operating temperature, sensitivity to fuel composition, poisoning, and response time limitations.

By increasing the reaction rates, plasma heating could significantly reduce size requirements for effective reforming, increase speed of response and increase fuel flexibility. A wide range of operation is possible, from partial oxidation to steam reforming. The boosting of the reaction rate would occur by creating a small high temperature region (5000-10000 K) where radicals are produced and by increasing the average temperature in an extended region.

The additional heating provided by the plasma can ensure a sufficiently high number of chemically reactive species, ionization states, and elevated temperatures for the partial oxidation reaction to occur with negligible soot production and with a high conversion of hydrocarbon fuel into hydrogen-rich gas. The effective conversion of hydrocarbon fuel is aided by both the high peak temperature in the plasma and the high turbulence created by the plasma.

The rapidly variable plasmatron parameters (energy input, flow rate, product gas composition, etc.) make this technology able to respond to the dynamic demands of vehicles. It should be practical to instantaneously produce hydrogen-rich gas for use during cold startup. Throughout the driving cycle, rapid changes in hydrogenrich gas flow can be accommodated by variation of plasmatron parameters. [8]

Figure 1 shows a diagram of a multi kilowatt plasmatron. The device operates at atmospheric pressure, with air as the plasma forming gas. The plasmatron operates in DC mode. The plasmatron consists of a copper cathode with a hafnium tip, and a copper tubular anode [14]. The electrodes are separated by an electrical insulator made out of fiberglass (G-10). The cathode and anode are water cooled, and this cooling represents a sink of energy. Measurements on the water temperature rise indicate that the plasmatron is about $70-80 \%$ efficient. Hafnium allows operation on air as the plasma forming gas. The hafnium tip has a high electron emissivity and relatively long lifetime using a current less than $100 \mathrm{~A}$.

The plasma arc ignites across the electrode gap. Air is injected tangentially upstream from the electrodes to produce a vortex that elongates the plasma inside the tubular anode. The anode root of the arc is in constant rotation in order to minimize electrode erosion. The hydrocarbon fuel and additional air are injected downstream from the electrodes. The mixture of hot air and vaporized hydrocarbons enter the plasma reactor where the reaction takes place.

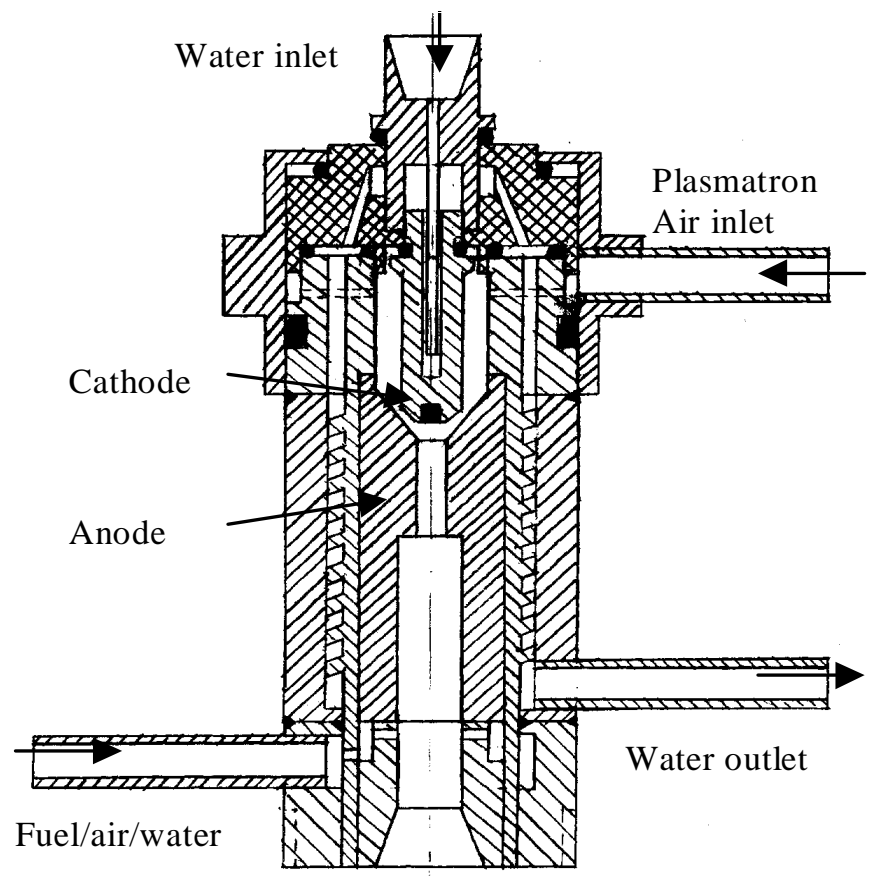

Figure 1. Plasmatron fuel converter device. Reaction extension cylinder and heat exchanger are not shown.

Figure 2 shows a photograph of a microplasmatron without a reaction extension cylinder, operating with air at about $1.5 \mathrm{~kW}$. The plasma jet is pointing vertically in the figure. During reforming operation, fuel and additional air are injected downstream from the stainless steel flange shown in Figure 2.

Figure 3 shows a microplasmatron fuel converter that includes a reaction extender and a heat exchanger. The heat exchanger can be used to simultaneously cool down the hydrogen-rich gas and to preheat the incoming air and fuel. Preheating the air and fuel reduces the electrical energy requirement to the plasmatron and increases the hydrogen yield. Work is continuing in the development of a high efficiency, high temperature heat recuperator. Simple calculations show that using preheat can reduce the electrical power requirements to the plasmatron by half.

A typical microplasmatron fuel converter includes a steel tube $4-\mathrm{cm}$ in diameter and $15-\mathrm{cm}$ long. It is thermally insulated by fiberglass felt and steel screens. The samples of hydrogen rich gas are cooled down and analyzed using gas chromatography (GC). Table 1 shows the typical plasmatron range of operating parameters for a DC arc device. Materials that could be used for various components of the plasma-boosted reformer are copper, zirconium and molybdenum. Conversion efficiency, electrode life, size, and weight are essential feasibility issues and require detailed experimental investigation. 


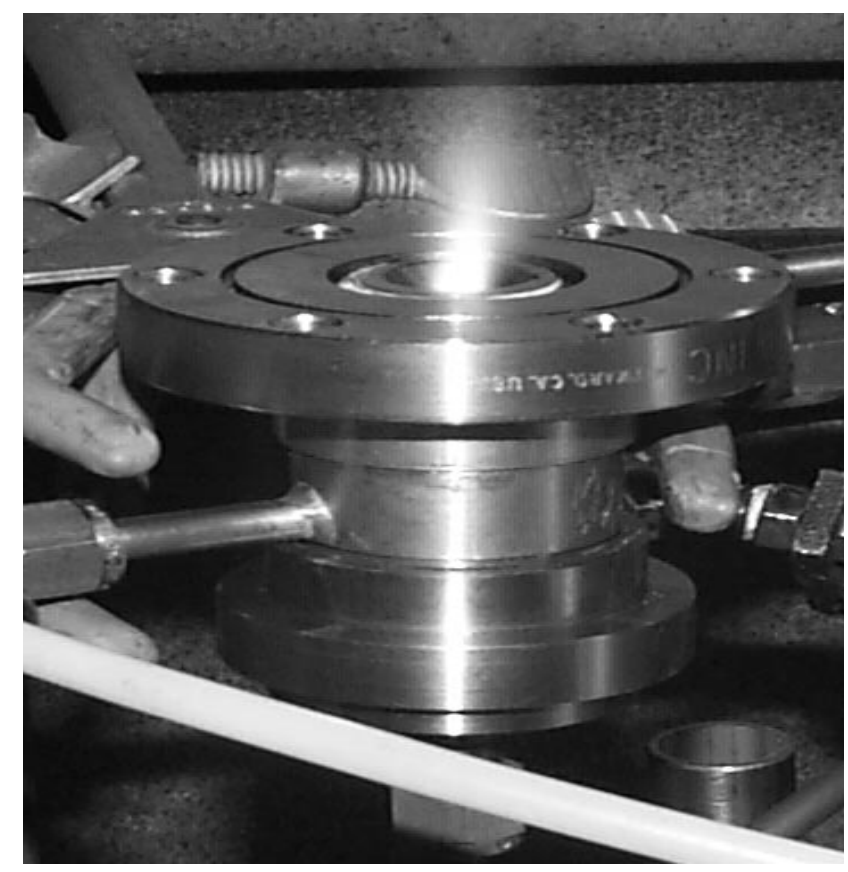

Figure 2. DC arc microplasmatron operating in air without fuel.

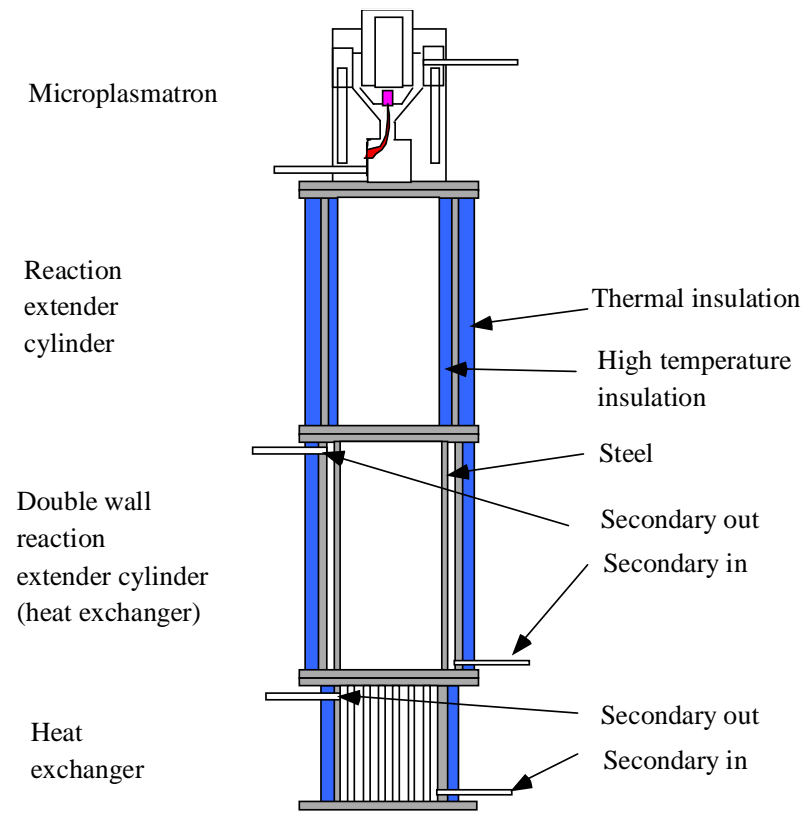

Figure 3. Microplasmatron with reaction extender cylinder and two heat exchangers.

Table 1. Parameters of conventional DC Arc plasma boosted reformer.

\begin{tabular}{|l|l|}
\hline Power & $1.5-10 \mathrm{~kW}$. \\
\hline Voltage & $120-140 \mathrm{~V} \mathrm{DC}$ \\
\hline Current & $15-75$ A DC \\
\hline $\begin{array}{c}\text { Flow rates } \\
\text { Air }\end{array}$ & $0.5-1.5 \mathrm{~g} / \mathrm{s}$ \\
\hline Fuel & $0.3-0.5 \mathrm{~g} / \mathrm{s}$ \\
\hline
\end{tabular}

The microplasmatron used in the engine experiments described in the following section is shown in Figure 3. The plasmatron is followed by a reaction extension cylinder, a simple heat exchanger (not cooled for the present experiments), and a gas-to-water heat exchanger, used to cool the reformate.

\section{GASOLINE AND DIESEL REFORMING}

Using a DC arc microplasmatron fuel converter, conventional fuels were very efficiently converted to hydrogen rich gas, with an electrical power input of $\sim 10 \%$ of the heating value of the fuel. However, with heat regeneration and with improved reactor design, it is estimated that the required electrical energy input to the microplasmatron fuel converter will be on the order of $5 \%$ of the heating value of the fuel. Furthermore, the reactor showed no evidence of soot, even after extended operation. Innovations to further decrease the energy consumption and to further simplify the microplasma reformer are described at the end of this discussion.

Figure 4 shows the specific energy consumption of the hydrogen rich gas produced by the DC Arc microplasmatron fuel converter, in units of $\mathrm{MJ} / \mathrm{kg} \mathrm{H} \mathrm{H}_{2}$ for diesel fuel. The hydrogen and light hydrocarbon yield as a function of oxygen to carbon ratio is shown in Figure 5 . At the higher oxygen to carbon ratios, the process becomes more exothermic. For a given specific electrical power input, the increase temperature increases the yield (as shown in Figure 5) and decreases the specific energy consumption.

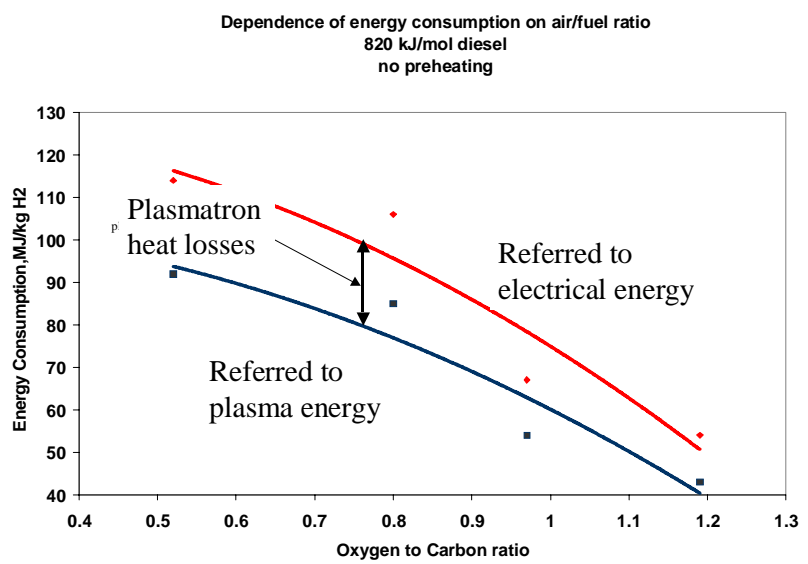

Figure 4. Energy consumption for plasma diesel reforming as a function of the oxygen to carbon ratio.

The experiments described above were conducted at constant power. The power requirements and the reformate composition were relatively insensitive to the flow rates as long as the specific power input (power/unit mass) and air/fuel ratios are kept constant. Under these circumstances, although the residence time decreases (because of the higher throughputs) increased efficiency 
of the system makes up for the decreased residence time. Figure 6 shows the composition of the reformate for diesel as the fuel, as a function of the oxygen to carbon ratio. The hydrogen concentration is relatively constant.

Microplasmatron fuel converters have substantial dynamic range. The lower power is determined by the maximum voltage capability of the power supply (the voltage increases with decreasing current), while the highest power is determined by erosion of the electrodes. It is expected that a dynamic range of a factor of 10 is possible without substantial modification to the plasmatron device. This is sufficient to provide the required change in throughput for conventional engines. For hybrid vehicles, with engines operating at constant or near constant conditions, the plasmatron fuel converter would operate at near constant conditions, with air/fuel/power management requirements that are much simpler than for conventional drive.

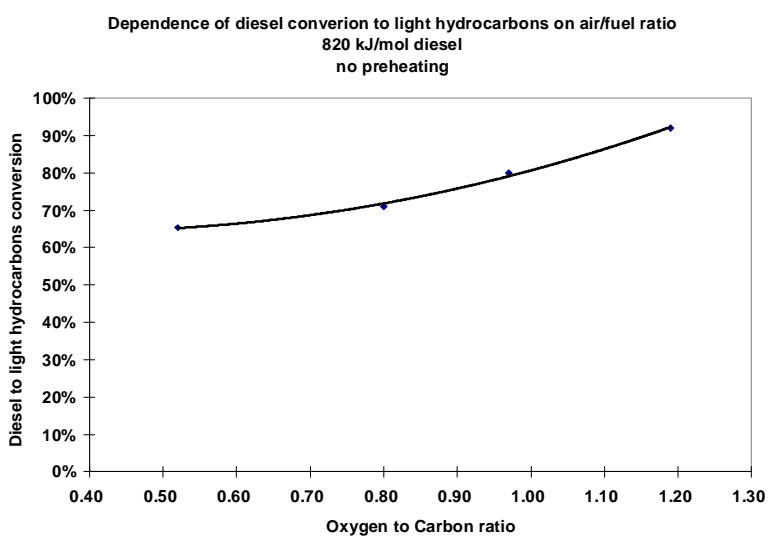

Figure 5. Hydrogen and light hydrocarbon yield as a function of the oxygen to carbon ratio.

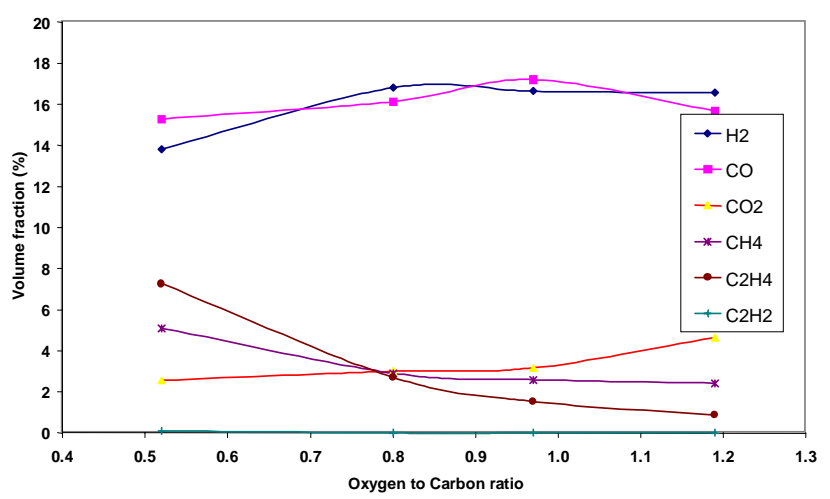

Figure 6. Composition of reformate as a function of the oxygen to carbon ratio, for diesel fuel.

Balance is $\mathrm{N}_{2}$.

\section{LOW CURRENT MICROPLASMATRON DEVICE}

A low current microplasmatron device that can operate at power levels as low as $10 \mathrm{~W}$ was developed. The size of the power supply was decreased and electrode wear was reduced. Figure 7 shows a schematic of the low current microplasmatron device used in the engine experiments described in the following section. During the engine experiments, the unit operated at $270 \mathrm{~W}$.

The low current microplasmatron consists of a central electrode, an insulator, and a tubular grounded electrode. The air-fuel mixture is introduced into the gap between the electrodes creating a plasma discharge with characteristics similar to those of a glow discharge $(500-1000 \mathrm{~V}$, 20-100 mA). The reaction is created by intimate contact of the air-fuel mixture with the discharge from the plasma and propagates through the reaction extension cylinder.

\section{ENGINE EXPERIMENTS}

Microplasmatron reforming experiments were conducted using a production in-line four-cylinder SI gasoline-fueled engine (1995 General Motors Quad-4) at Oak Ridge National Laboratory (ORNL). The Quad4 has a 2.3-L displacement, $9.2-\mathrm{cm}$ bore, $8.5-\mathrm{cm}$ stroke, and compression ratio of 9.5. This engine is port-fuel-injected and does not utilize a turbocharger or exhaust gas recirculation. The engine was coupled to a 130-kW (175-hp) eddy-current (Power Dyne, Inc.) dynamometer for engine speed and load control. Engine control management was carried out with a TEC-II control system (Electromotive, Inc.) The TEC-II provided access to all calibration parameters (base fuel curve, enrichment, and spark advance) for proper engine operation. The TEC-II control allows the user to set a desired air/fuel ratio. It can also adjust the fuel automatically to maintain stoichiometric air/fuel ratio by monitoring the exhaust gas oxygen.

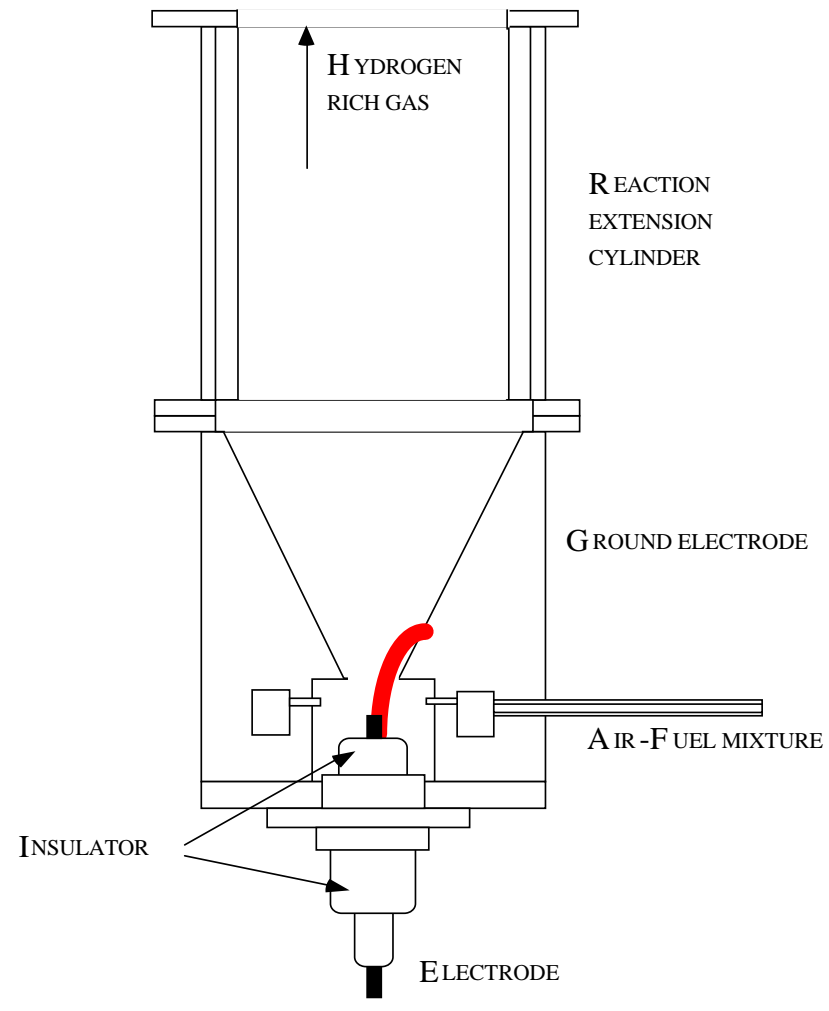

Figure 7. Schematic of the low current microplasmatron fuel converter. 
Along with engine operating parameters and in-cylinder pressure, engine out regulated emissions $(\mathrm{CO}, \mathrm{HC}$ and $\mathrm{NO}_{\mathrm{x}}$ ) and PM were measured at each operating point. Total mass concentration and rate of PM was measured with a Tapered Element Oscillating Microbalance (TEOM, $\mathrm{R}$ and $\mathrm{P}$ Co. Model 1105). A scanning mobility particle sizer (SMPS, TSI, Inc.) measured PM size and number. CARB Phase II certification grade gasoline was used for engine and plasmatron operation. The gasoline equivalent air/fuel ratio was measured with a universal exhaust gas oxygen (UEGO) sensor (Horiba MEXA 110) in the exhaust stream. Therefore during reformate addition, the reported equivalence ratio from the UEGO sensor is higher (richer) than the actual equivalence ratio because of the effect of burning both gasoline from the engine and reformate from the microplasmatron on the UEGO sensor.

The microplasmatron was operated with a constant gasoline throughput of $0.25 \mathrm{~g} / \mathrm{s}$. The reformate was cooled down to room temperature by a low-pressure shell-intube heat exchanger. The composition of the microplasmatron output was continuously monitored using a conventional tailpipe emissions monitor (Horiba MEXA 554). Table 2 shows the measured parameters of the microplasmatron during experiments conducted at ORNL and MIT. The electrical power input to the microplasmatron was about $2 \%$ of the heating value of the fuel processed. This microplasmatron incorporated several design improvements that will be discussed in a later publication.

Table 2. Operating conditions for the microplasma reformer.

$\begin{array}{ccc}\begin{array}{c}\text { MIT } \\ \text { Fuel Flow Rate, } \mathrm{g} / \mathrm{s}\end{array} & \begin{array}{c}\text { ORNL } \\ \text { (Horiba) }\end{array} \\ \begin{array}{c}\text { Composition of reformate } \\ \mathrm{NO}\end{array} & 0.25 \\ \mathrm{CO}_{2} & 20 \% & 18-21 \% \\ \mathrm{CH}_{4} & 3.5 \% & 4 \% \\ \mathrm{C}_{2} \mathrm{H}_{4}+\mathrm{C}_{2} \mathrm{H}_{6} & 0.5 \% & \mathrm{NA} \\ \mathrm{H}_{2} & 0.2 \% & \mathrm{NA} \\ \mathrm{N}_{2} & 16 \% & \mathrm{NA} \\ \mathrm{HC} \text { by FID }\left(\mathrm{ppm} \mathrm{C} \mathrm{C}_{3}\right) & 60 \% & \mathrm{NA} \\ & \mathrm{NA} & 260-410\end{array}$

Experiments were conducted at two engine operating conditions: the first one at $2300 \mathrm{rpm}$ and 4.2 bar brake mean effective pressure (BMEP); and the second one at $1500 \mathrm{rpm}$ and 2.6 bar BMEP. Maximum brake torque (MBT) spark timing was defined for both operating conditions at stoichiometric conditions with the engine in closed-loop control mode. Once the MBT spark timing was defined for each condition, spark timing remained fixed as air/fuel ratio was increased with the engine in open-loop control mode. BMEP was also kept constant as air/fuel ratio was increased.

Reformate was introduced into the engine via the intake manifold downstream of the throttle. The overall hydrogen addition was relatively small, being about $4 \%$ of fuel heating value at the $2300 \mathrm{rpm}$ condition and about $9 \%$ at the $1500 \mathrm{rpm}$ condition. The maximum reformate flow rate was determined by heat removal limitations of the plasmatron reactor. Bench top tests are being conducted in the laboratory to remove this limitation.

\section{RESULTS AND DISCUSSION}

Figures 8 and 9 show the Coefficient of Variation of the gross Indicated Mean Effective Pressure (COV of IMEP) as a function of equivalence ratio for the two operating conditions. Both cases of baseline operation (without reformate addition) and the case with reformate addition are shown in the figures. The equivalence ratio in these figures has been determined from the exhaust gas composition. The presence of hydrogen in the engine substantially reduces the COV of IMEP, even at the $2300 \mathrm{rpm}$ condition, when the reformate addition is a small fraction of the total fuel.

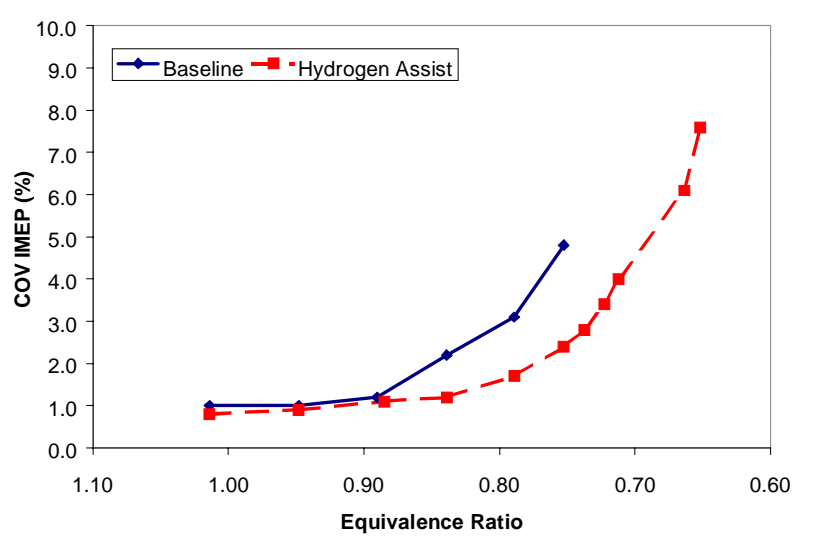

Figure 8. COV of IMEP as a function of exhaust equivalence ratio (1500 rpm, 2.6 bar BMEP).

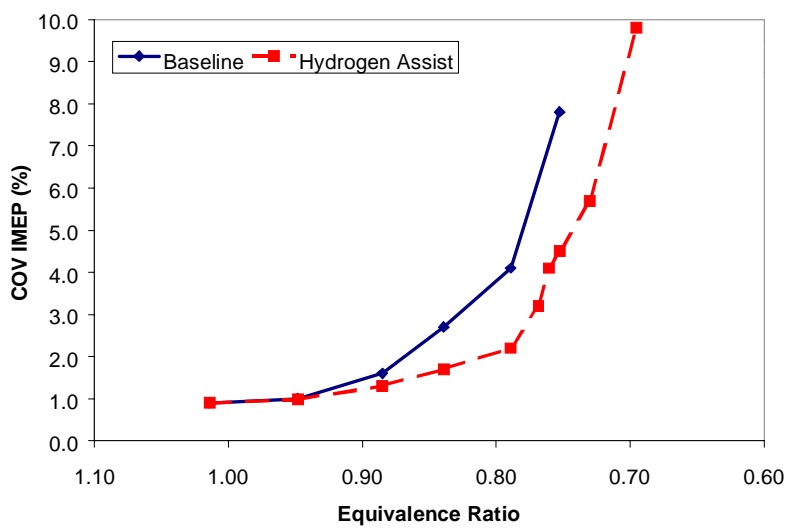

Figure 9. COV of IMEP as a function of exhaust equivalence ratio (2300 rpm, 4.2 bar BMEP).

Figures 10 and 11 show the $\mathrm{NO}_{\mathrm{x}}$ emissions as a function of the COV of IMEP. The plots illustrate the reduction of $\mathrm{NO}_{\mathrm{x}}$ emissions within acceptable levels of cycle-to-cycle combustion variations ( 3 to $5 \% \mathrm{COV}$ of IMEP). The $\mathrm{NO}_{\mathrm{x}}$ concentration decreases with the reformate addition for a given COV of IMEP, even with relatively small reformate addition. At a COV of $5 \%, \mathrm{NO}_{\mathrm{x}}$ is reduced by a factor of 
about a hundred by the addition of plasma boosted reformer generated hydrogen at $1500 \mathrm{rpm}$ engine operation. Higher reformate addition may be necessary, especially for the higher load cases. The plasma-boosted reformer is presently being modified to provide increased hydrogen generation.

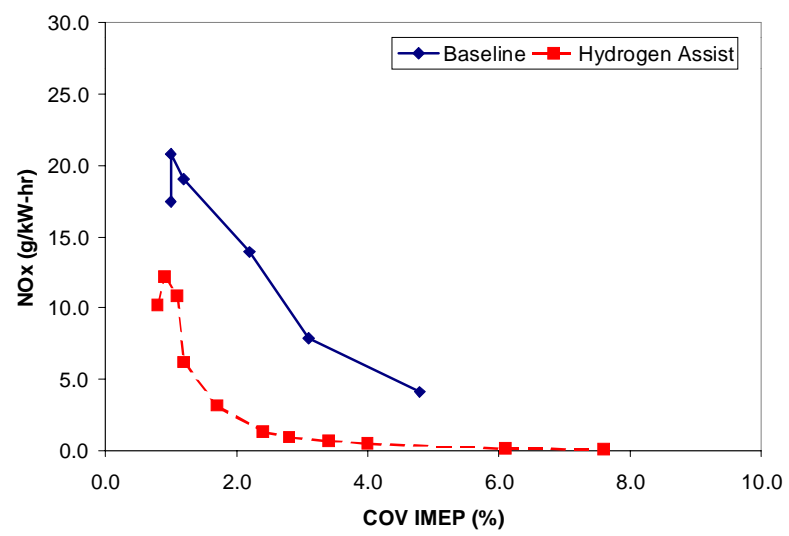

Figure 10. NOx emissions as a function of the COV of IMEP (1500 rpm, 2.6 bar BMEP).

The corresponding concentration of hydrocarbons is shown in Figures 12 and 13, for the 1500 and 2300 rpm operating conditions, respectively. Decreases in HC emissions of about $20-30 \%$ are possible. Larger effects could be possible with the additional of increased amounts of hydrogen rich gas.

Particulate mass emissions as measured by the TEOM showed very low values for both the baseline and reformate addition cases. Figure 14 shows the relative mass emissions decrease from the baseline stoichiometric case. Although the TEOM was approaching its lower sensitivity limits, the trend is still clear; decreasing equivalence ratio leads to lower PM mass emissions. In addition to PM mass, PM size distribution was measured. Figure 15 shows that there appears to be an increase in particle number with decreasing equivalence ratio. Although this seems to contradict the PM mass emissions decrease, the proportion of larger diameter (and heavier) particles decreases with decreasing equivalence ratio.

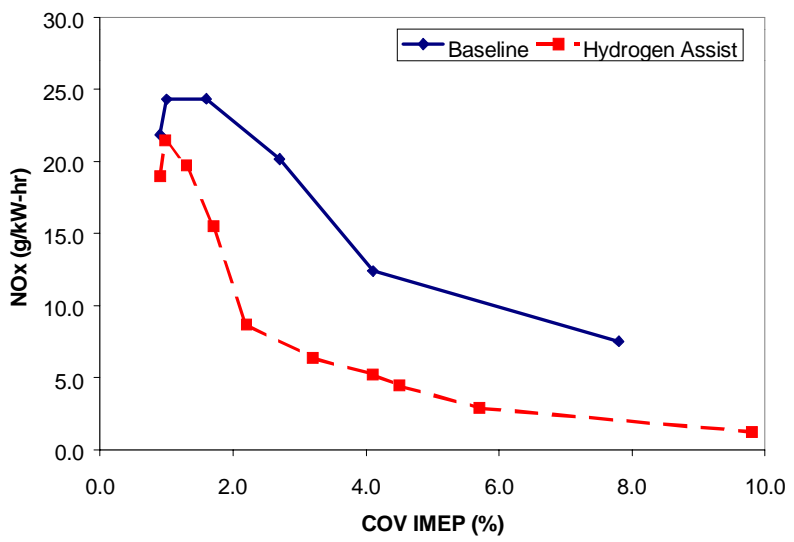

Figure 11. NOx emissions as a function of the COV of IMEP (2300 rpm, 4.2 bar BMEP).
Use of the microplasmatron caused a relatively small decrease in thermal efficiency (see Figures 16 and 17). Thermal efficiency was degraded because of the fuel that is reformed and the microplasmatron electrical power consumption. When the proportion of plasmatron output is higher (e.g., the $1500 \mathrm{rpm}$ engine condition), the efficiency penalty is reduced at lower equivalence ratios due to improved combustion stability.

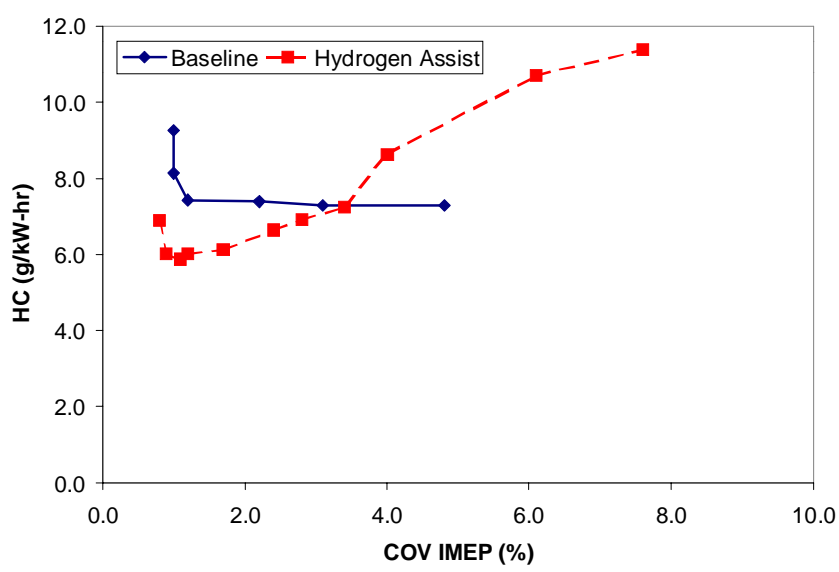

Figure 12. Hydrocarbon emissions as a function of the COV of IMEP (1500 rpm, 2.6 bar BMEP).

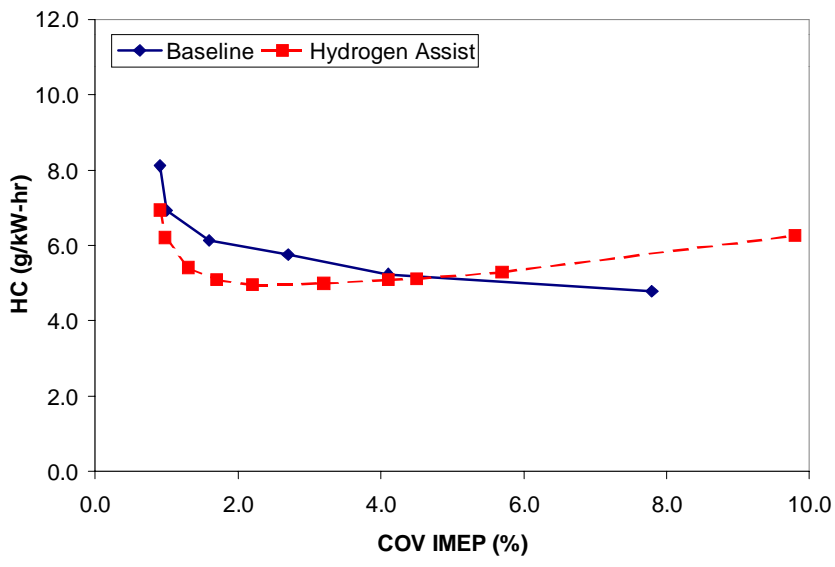

Figure 13. Hydrocarbon emissions as a function of the COV of IMEP (2300 rpm, 4.2 bar BMEP).

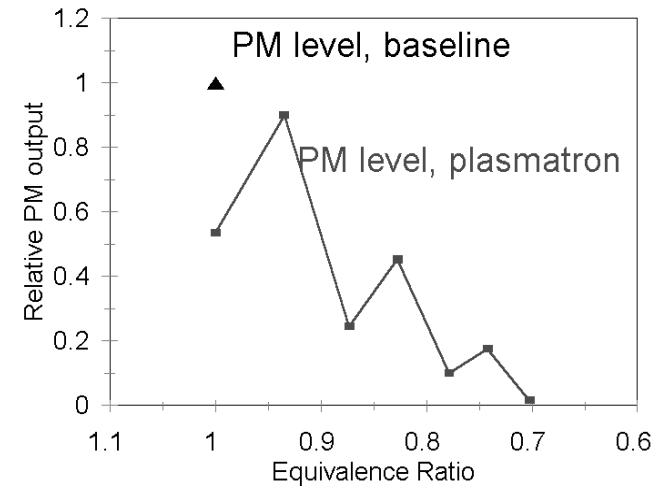

Figure 14. Relative PM emissions as a function of equivalence ratio (1500 rpm, 2.6 bar BMEP). 


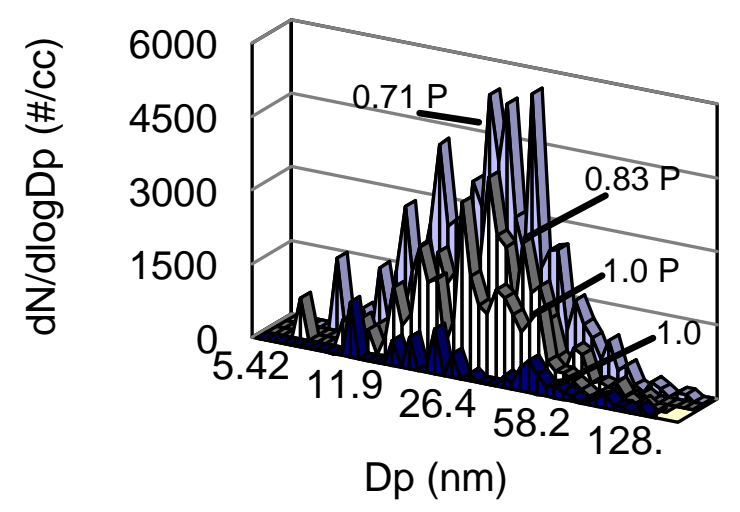

Figure 15. Particle size distribution for four different equivalence ratios (designated by labels) at 1500 rpm, 2.6 bar BMEP. P designates hydrogen assist. Note the overall numbers are very low.

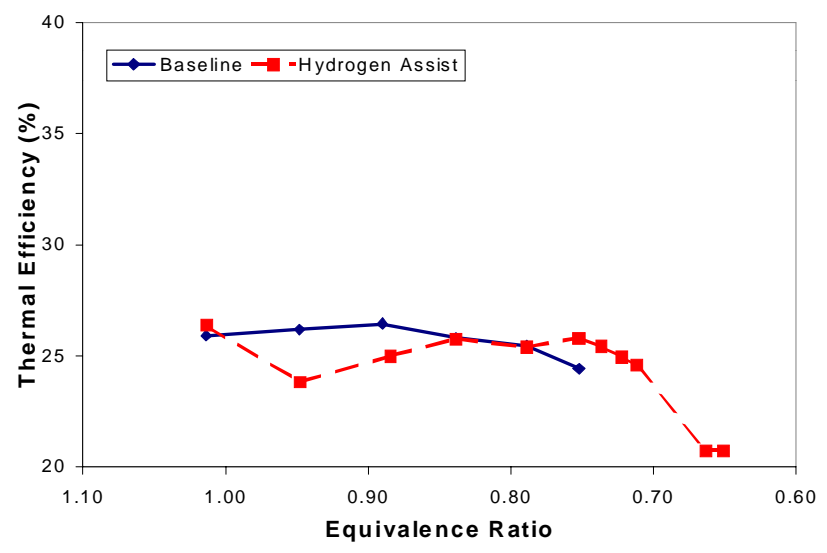

Figure 16. Engine thermal efficiency as a function of equivalence ratio (1500 rpm, 2.6 bar BMEP).

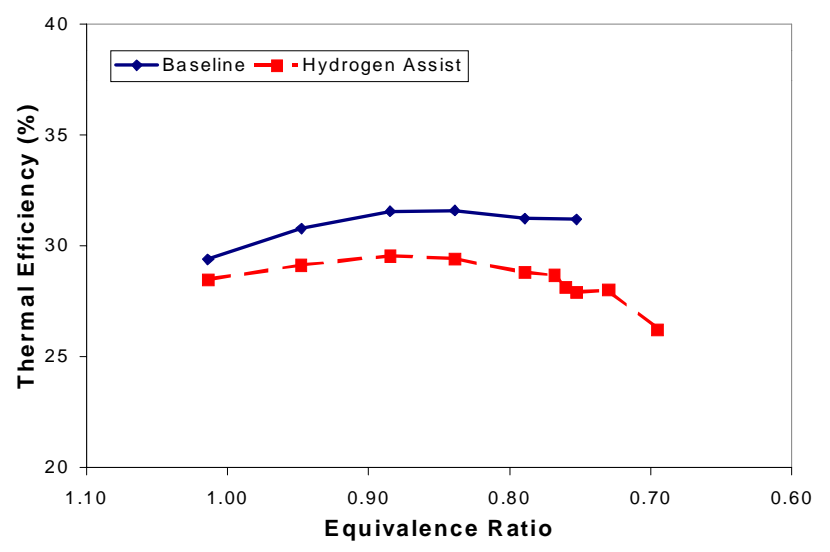

Figure 17. Engine thermal efficiency as a function of equivalence ratio (2300 rpm, 4.2 bar BMEP).

\section{DISCUSSION}

The addition of reformate stabilized engine operation under lean fueling, resulting in lower $\mathrm{NO}_{\mathrm{x}}$ emissions. Similar results should be obtainable with reformate addition at high EGR levels. The exhaust gas has a larger heat capacity than air (due to the higher concentration of tri-atom molecules in the exhaust gas), and therefore $\mathrm{NO}_{x}$ reduction with $\mathrm{EGR}$ should be larger than with air [1]. Tests are being planned to investigate the effects of EGR with reformate addition.

In a similar fashion to other reformer concepts such as those used for reforming ethanol [12,13], the plasmaboosted reformer is also ideally suited for cold-start conditions, due to the rapid response time of the microplasmatron. The time of microplasmatron operation without preheat and with a high fraction of fuel to the device is limited to cold start and is thus very small. During cold start, a high fraction of the fuel would be converted into hydrogen-rich gas. As soon as the catalyst is warmed up, the fraction of processed fuel would be decreased.

\section{CONCLUSIONS}

Onboard generation of hydrogen-rich gas using a plasma-boosted microreformer could provide important new opportunities for significantly reduced emissions. A compact plasma boosted reformer was successfully integrated with a gasoline engine on an engine test stand. SI engine experiments were carried out to determine the effect of reformate addition on emission and efficiency. $\mathrm{NO}_{\mathrm{x}}$ emissions reduction of two orders of magnitude was obtained. The plasma boosted microreformer operated reliably for the relatively long duration of the experiments ( $>6$ hours per day), operating on gasoline. Additional effort is required to decrease the electromagnetic noise, as well as to better integrate the microplasmatron fuel converter with the engine. The rapid response, as well as the robustness to fuel characteristics and ambient temperature, makes the plasma-boosted microreformer suitable as a fuel converter for a variety of onboard applications.

\section{ACKNOWLEDGMENTS}

This work was supported by the Office of Heavy Vehicle Technologies (OHVT), U.S. Department of Energy. Dr. Sid Diamond and Mr. Richard Wares of DOE-OHVT provided valuable guidance and support for this project. Oak Ridge Natioinal Laboratory is managed by UT-Battelle, LLC, under contract no. DE-AC05-00OR22725. 


\section{REFERENCES}

1. Heywood, John B., Internal Combustion Engine Fundamentals, McGraw Hill, 1988.

2. Breshears, R., Cotrill, H. and Rupe, T., Partial Hydrogen Injection into Internal Combustion Engines Proc EPA 1st Symp on Low Pollution Power Systems Development, Ann Arbor, MI Oct (1973).

3. MacDonald, J.S., Evaluation of the Hydrogen-Supplemented Fuel Concept with and Experimental Multicylinder Engine, SAE Paper 760101 (1976).

4. H.S. Homan et al., The Effect of Fuel Injection on NOx Emissions and Undesirable Combustion of Hydrogen Fueled Piston Engines, Int $\mathrm{J}$ of Hydrogen Ener 8 (1983).

5. Kuroda, H., Nakajima, Y., Sugihara, K, Takagi, Y. and Muranaka, S. The Fast Burn with Heavy EGR, New Approach for Low NOx and Improved Fuel Economy, Society for Automotive Engineers, Paper 780006 (1979).

6. A. Rabinovich, D.R. Cohn and L. Bromberg, Plasmatron Internal Combustion Engine System for Vehicle Pollution Reduction Int J. Vehicle Design 15234 (1995).

7. D.R. Cohn, A. Rabinovich and C. H. Titus, Onboard Plasmatron Operation Generation of Hydrogen for Extremely Low Emission Vehicles with Internal Combustion Engines, Int. J. Vehicle Design 17550 (1996).
8. D.R. Cohn, A. Rabinovich, C.H. Titus and L. Bromberg, Near Term Possibilities for Extremely Low Emission Vehicles using On-Board Plasmatron Generation of Hydrogen, Int. J Hydrogen Ener 22715 (1997).

9. L. Bromberg, D.R. Cohn, A. Rabinovich, J.E. Surma, J. Virden, Compact Plasmatron-Boosted Hydrogen Generation Technology for Vehicular Applications, J. Hydrogen Energy 24341 (1999).

10. J.E. Kirwan, A. Quader and M.J. Grieve, Advanced Engine Management Using On-Board Gasoline Partial Oxidation Reforming for Meeting Super-ULEV (SU-LEV) Emissions Standards, SAE Paper 199901-2927 (1999).

11. A. Smith and G.J.J. Bartley, Stoichiometric Operation of a Gas Engine Utilizing Synthesis Gas and EGR for NOx Control, ASME ICE- 29-3, Engine Combustion Performance and Emission (1997).

12. K. Dobrot Isherwood, J.R. Linna and P.J. Loftus, Using Onboard Fuel Reforming by Partial Oxidation to Improve SI Engine Cold-Start Performance and Emissions, SAE Paper 980939 (1998).

13. J. W. Hodgson, D.K. Irick, and M.V. Whalen, Improving the cold-start performance of alcohol-fueled engines using a rich combustor, SAE Paper 981359 (1998).

14. Rudiak, E.M., A. Rabinovich, and N.A. Tul, USSR Patent 700935, Aug. (1979). 